\title{
Parálisis facial: ¿Siempre parálisis de Bell?
}

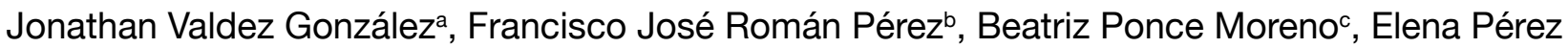 \\ Guerrad $^{\mathrm{d}}$, Vicente Martín Díaz
}

\begin{abstract}
${ }^{a}$ MIR de Medicina de Familia. Unidad Docente de Atención Familiar y Comunitaria de Toledo. Centro de Salud "Santa Bárbara"

b Médico de Familia. Centro de Salud "Santa Bárbara" de Toledo

c EIR de Enfermería Geriátrica. Unidad Docente Multidisciplinar del Complejo Hospitalario de Toledo

d Médico de Familia. Centro de Salud de Sonseca (Toledo)

e Enfermero. Centro de Salud

"Santa Bárbara" de Toledo
\end{abstract}

Correspondencia: Jonathan Valdez González

E-mail: jonatva@gmail.com

Recibido el 1 de octubre de 2013.

Aceptado para su publicación el 15 de octubre de 2013.

\section{RESUMEN}

La parálisis facial periférica es un motivo de consulta relativamente frecuente en Atención Primaria, afectando de forma similar a hombres y mujeres. La parálisis facial periférica más frecuente es la de causa idiopática o parálisis de Bell, en un $70 \%$ de los casos. Otras etiologías menos frecuentes son los traumatismos, infección por virus o la posible causa neoplásica, ya sea por un tumor intracraneal o extracraneal.

La sintomatología clínica más relevante es la afectación de la musculatura facial existiendo una recuperación completa hasta en el $80 \%$ de los casos. El tratamiento depende de la etiología, siendo el más aceptado para la parálisis de Bell el uso de corticoides.

Presentamos el caso de una paciente joven con parálisis facial refractaria al tratamiento en Atención Primaria.

Palabras clave: Parálisis facial periférica, parálisis de Bell, ángulo pontocerebeloso, tumores epidermoides

\section{ABSTRACT}

Facial paralysis: Always Bell's palsy?

Peripheral facial paralysis is a relatively common reason for primary care consultations, affecting males and females similarly. The most common peripheral facial paralysis is that of idiopathic origin or Bell's palsy, in $70 \%$ of cases. Other less frequent aetiologies are injuries, viral infections or a possible neoplastic cause, whether from an intra-cranial or extra-cranial tumour. The most important clinical symptom is that affecting the facial muscles, with a full recovery in up to $80 \%$ of cases. Treatment is dependent on aetiology, with the most widely accepted being that for Bell's palsy; the use of corticosteroids.

We present the case of a young female patient with refractory facial paralysis under primary healthcare treatment.

Key words: Peripheral facial paralysis, Bell's palsy, cerebellopontine angle, epidermoid tumors.

\section{INTRODUCCIÓN}

La parálisis facial periférica en una enfermedad relativamente frecuente en la población general, estimándose una incidencia anual de 23/100.000 habitantes. Es uno de los motivos de consulta clínica más alarmante para el paciente provocándole importante ansiedad ${ }^{1}$.

Consiste en una debilidad o pérdida de función de la musculatura inervada por el nervio facial (VII par craneal). Esto da lugar a una disminución parcial o completa de la motilidad voluntaria de la cara, imposibilidad para cerrar el globo ocular y desviación de la comisura labial al lado contralateral ${ }^{1,2}$.

La parálisis de Bell o parálisis facial idiopática es la forma más frecuente (60$75 \%)$ de parálisis facial periférica. Afecta a ambos sexos por igual y puede aparecer a cualquier edad, con una incidencia máxima entre los 10 y los 45 años ${ }^{1,3,4}$.

Otras causas menos frecuentes de parálisis facial son los traumatismos, infección por virus o la posible causa neoplásica, ya sea por un tumor intracraneal o extracraneal, entre otras ${ }^{5}$. 
Entre el $73 \%$ y el $84 \%$ de las parálisis de Bell (PB) se recuperan sin tratamiento alguno, por lo que algunos autores recomiendan no tratarla ${ }^{1}$. Sin embargo, según otros autores, la instauración de un tratamiento precoz y correcto puede disminuir por un lado el dolor y por otro el grado e intensidad de la denervación y sus secuelas. El tratamiento más aceptado siguen siendo los corticoides en dosis de $1 \mathrm{mg} / \mathrm{kg} /$ día $^{6,7}$.

\section{OBSERVACIONES CLÍNICAS}

Paciente mujer de 18 años con antecedente personal de hipotiroidismo subclínico idiopático sin tratamiento hormonal sustitutivo y hernia umbilical intervenida en la infancia. Consulta por parálisis facial periférica derecha de instauración súbita sin otalgia, hipoacusia ni acúfenos. No presencia de cefalea ni síntomas neurológicos asociados.

La exploración física general fue normal. En la exploración neurológica la paciente estaba consciente, alerta, reactiva, orientada en las tres esferas, pupilas isocóricas y normorreactivas, no presentaba rigidez de nuca ni otros signos meníngeos, desviación de la comisura bucal hacia la izquierda junto con signo de Bell y signo de la pestaña positivos, así como disminución de las arrugas de la frente del lado derecho (figura 1), fuerza y sensibilidad conservadas y simétricas, reflejos osteotendinosos normales, no presentaba dismetrías ni disdiadococinesias, los signos de Romberg y Barany no eran patológicos, reflejo cutáneo-plantar flexor y marcha normal. Resto de la exploración neurológica totalmente anodina.

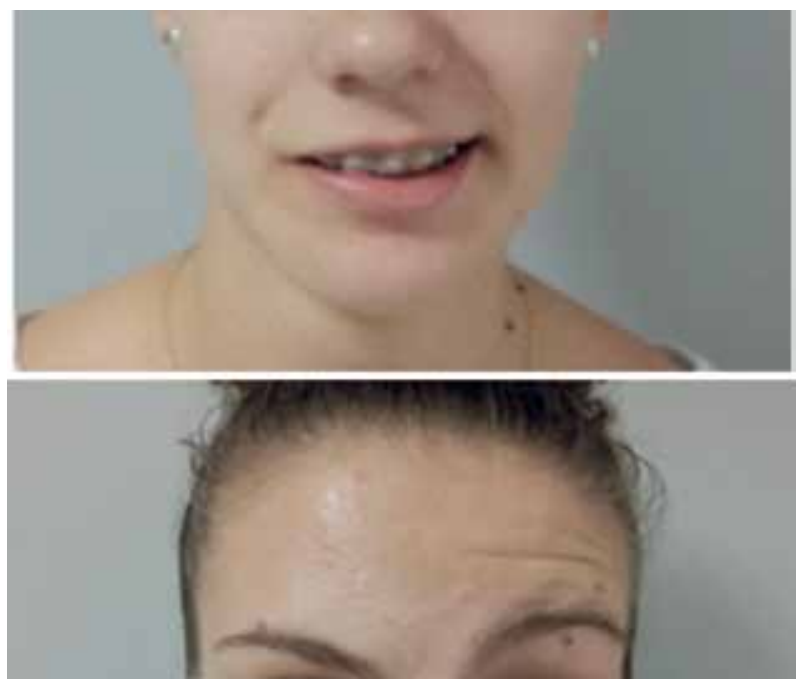

Figura 1. Figura 1. Signos de parálisis facial

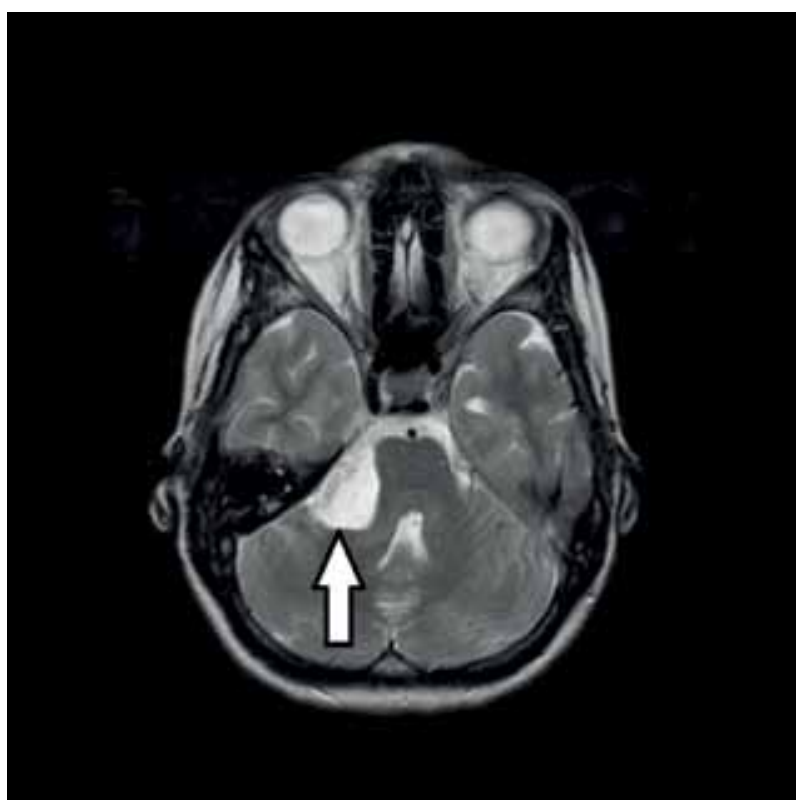

Figura 2. RNM craneal. La flecha indica lesión compatible con quiste epidermoide en ángulo pontocerebeloso derecho

Bajo el diagnóstico de parálisis facial periférica, iniciamos tratamiento con dosis de corticoides vía oral (1 mg/kg/día), masaje facial y protección ocular, presentando una ligera mejoría en los 4 primeros días. Posteriormente evolucionó hacia un empeoramiento de su sintomatología, siendo la exploración neurológica en todo momento similar a la del diagnóstico del caso, motivo por el cual tras 2 semanas de tratamiento se decidió valoración con carácter preferente por el servicio de Otorrinolaringología (ORL).

Tras valoración por ORL se llegó a la misma conclusión diagnóstica de parálisis facial periférica recomendando continuar con el tratamiento prescrito en nuestra consulta de atención primaria (corticoides más tratamiento no farmacológico) y revisión de la paciente a los 15 días. Tras estos y ante la no mejoría del cuadro clínico el ORL decidió solicitar Resonancia Magnética Nuclear (RMN) y su derivación al servicio de Rehabilitación.

En la RMN craneal se objetivo lesión compatible con quiste epidermoide en ángulo pontocerebeloso derecho y fue remitida a neurocirugía donde, tras ser valorada, se decide realizar extirpación quirúrgica. (Figura 2).

La paciente fue intervenida bajo anestesia general realizándose abordaje retrosigmoideo derecho y extirpación completa de la lesión con preservación y descompresión de VII par. La intervención fue bien tolerada y sin incidentes. Tras once días 
recibió el alta pese a persistir discreta cefalea, encontrándose en la actualidad completamente asintomática.

\section{COMENTARIOS}

La parálisis facial idiopática representa uno de los motivos más frecuentes de consulta neurológica en atención primaria. La evolución natural del cuadro es hacia la resolución del mismo, presentando por tanto un buen pronóstico ${ }^{1,7}$. Siempre debemos tener la precaución de descartar una posible causa orgánica a dicha parálisis facial tal y como ocurrió en el caso clínico expuesto anteriormente.

Aproximadamente el 6 a $10 \%$ de todos los tumores intracraneales se localizan en el ángulo pontocerebeloso (APC) y la mayoría de estos (el $80 \%$ ) son schwannomas vestibulares. Los meningiomas y los quistes epidermoides representan el $10 \%$ y el $6 \%$, respectivamente, y el resto consisten en un grupo sumamente heterogéneo de tumores que afectan la región. Los quistes epidermoides representan 0,2 al 1,8\% de todas las neoplasias intracraneales. No se asocian con otras anormalidades congénitas ${ }^{8}$.

Los tumores de gran tamaño en el APC pueden causar déficits funcionales en cualquiera de los nervios craneales que atraviesan el ángulo o las estructuras que forman parte de sus límites, el puente y el cerebelo. De esta manera, estos tumores causan sensación facial y corneal alterada, nistagmus, ataxia, parálisis facial, etc ${ }^{8}$.

A causa de su lento crecimiento, los quistes epidermoides del APC pueden ser asintomáticos muchos años. La duración media de síntomas se extiende de 1 a 8 años aproximadamente. La pérdida de audición es poco frecuente en comparación con los schwannomas vestibulares y predominan los síntomas del nervio facial que son rápidamente progresivos. Otros síntomas menos comunes son la neuralgia del trigémino, el entumecimiento o espasmo facial, signos cerebelares o signos de presión intracraneal elevada ${ }^{8,9}$.

El tratamiento de los quistes epidermoides del APC consiste, básicamente, en microcirugía y su pronóstico depende del grado de extensión en el momento del diagnóstico ${ }^{8-10}$.

A raíz de todo lo expuesto, nos gustaría destacar que no toda exploración neurológica compatible con una parálisis facial periférica de posible origen idiopático es suficiente para descartar organicidad del cuadro clínico. Se deben tener en consideración otros aspectos, no menos importantes, como la evolución y la progresión de dicho cuadro clínico, así como la mala respuesta al tratamiento prescrito.

Es por ello, y a tenor de la bibliografía consultada, que seria conveniente, como norma general, derivar a ORL a todo paciente con pobre respuesta clínica tras 15-20 días de tratamiento ${ }^{11}$.

\section{BIBLIOGRAFÍA}

1. Cinesi Gómez C, Caballero Sánchez MM, Álvarez de los Heros F. Parálisis facial periférica en atención primaria. Semergen. 2003;29:350-4.

2. Santos-Lasaosa S, Pascual-Millán LF, Tejero-Juste C, Morales-Asín F. Parálisis facial periférica: etiología, diagnóstico y tratamiento. Rev Neurol. 2000;30:1048-1053.

3. De Diego-Sastre JJ, Prim-Espada MP, Fernández-García F. Epidemiología de la parálisis de Bell. Rev Neurol. 2005;41:287-90.

4. Holland NJ, Weiner GM. Recent developments in Bell's palsy. BMJ. 2004;329:553-57.

5. Finsterer J. Management of peripheral facial nerve palsy. Eur Arch Otorhinolaryngol. 2008;265:743-52.

6. Sullivan FM, Swan IR, Donnan PT, Morrison JM, Smith BH, McKinstry $B$, et al. Early treatment with prednisolone or acyclovir in Bell's palsy. N Engl J Med. 2007;357:1598-607.

7. Colbert S, Coombes D, Godden D, Cascarini L, Kerawala C, Brennan PA. How do i manage an acute injury to the facial nerve? Br J Oral Maxillofac Surg (2013), http://dx.doi. org/10.1016/j.bjoms.2013.09.006

8. Springborg JB, Poulsgaard L, Thomsen J. Nonvestibular schwannoma tumors in the cerebellopontine angle: a estructured approach and management guidelines. Skull Base. 2008;18:217-27.

9. Chowdhury FH, Haque MR, Sarker MH. Intracraneal epidermoid tumor; microneurosurgical management: an experience of 23 cases. Asian J Neurosurg. 2013;8:21-28.

10. Cossetti $M K, X u M$, Rivera $A$, Jethanamest $D$, Kuhn MA, Beric A, et al. Intraoperative transcranial motorevoked potential monitoring of the facial nerve during cerebellopontine angle tumor resection. J Neurol Surg B. 2012;73:308-315.

11. Alonso MR. Parálisis facial. En: Espinas Boquet $\mathrm{J}$, editor. Guía de actuación en atención primaria. 3a ed. Barcelona: SEMFYC; 2006. p. 364-368. 